Table 1. Primary and secondary efficacy endpoints and post-hoc analyses, Week 52

\begin{tabular}{|c|c|c|c|c|c|c|c|}
\hline Group, by IST treatment & Cohort & $\mathbf{N}$ & $\Delta \mathrm{mRSS}$, mean (SD) & $\Delta \mathrm{FVC} \%$ mean (SD) & $\Delta \mathrm{FVC}, \mathrm{mL}$ mean (SD) & $\triangle \mathrm{HAQ}-\mathrm{DI}$ mean $(\mathrm{SD})$ & ACR CRISS median \\
\hline \multicolumn{8}{|c|}{ mITT population, MMRM primary analysis method } \\
\hline \multirow[t]{2}{*}{ All } & Placebo & 123 & $-8.1(7.72)$ & $-1.0(8.68)$ & $-51(317)$ & $-0.13(0.468)$ & 0.887 \\
\hline & Lenabasum 20 mg & 120 & $-6.7(6.59)$ & $-1.6(6.91)$ & $-78(265)$ & $-0.13(0.436)$ & 0.888 \\
\hline \multicolumn{8}{|c|}{ Placebo subjects, per protocol completers, LOCF } \\
\hline No IST & Placebo & 16 & $-2.3(9.4)$ & $-2.8(7.4)$ & $-97(244)$ & $0.12(0.34)$ & 0.417 \\
\hline All IST & Placebo & 97 & $-8.9(7.07)$ & $-1.0(9.2)$ & $-43(330)$ & $-0.17(0.474)$ & 0.936 \\
\hline MMF, no other IST & Placebo & 29 & $-10.7(8.1)$ & $-0.58(7.1)$ & $-37(235)$ & $-0.12(0.456)$ & 0.935 \\
\hline MMF $\leq 2$ years, no other IST & Placebo & 23 & $-11.7(8.1)$ & $-0.3(6.0)$ & $-41(197)$ & $-0.13(0.495)$ & 0.935 \\
\hline Non-MMF $\leq 2$ years & Placebo & 24 & $-6.7(6.2)$ & $-1.4(7.87)$ & $-52(281)$ & $-0.15(0.357)$ & 0.931 \\
\hline \multicolumn{8}{|c|}{ Post-hoc comparisons, per protocol completers, LOCF } \\
\hline \multirow{2}{*}{ No IST } & Placebo & 16 & $-2.3(9.4)$ & $-2.8(7.4)$ & $-97(244)$ & $0.12(0.34)$ & 0.417 \\
\hline & Lenabasum 20 mg & 10 & $-6.3(6.02)$ & $-2.3(5.58)$ & $-99(209)$ & $-0.06(0.498)$ & 0.811 \\
\hline \multirow[t]{2}{*}{ Established IST1 } & Placebo & 26 & $-6.1(5.35)$ & $-4.6(10.11)$ & $-170(350)$ & $-0.17(0.445)$ & 0.619 \\
\hline & Lenabasum $20 \mathrm{mg}$ & 38 & $-7.4(5.08)$ & $0.4(5.70)^{2}$ & $-21(233)^{3}$ & $-0.07(0.357)$ & 0.941 \\
\hline \multirow[t]{2}{*}{ Established IST, subjects with ILD } & Placebo & 22 & $-5.9(5.28)$ & $-3.7(5.43)$ & $-133(206)$ & $-0.10(0.372)$ & 0.553 \\
\hline & Lenabasum $20 \mathrm{mg}$ & 33 & $-7.2(5.70)$ & $-1.0(10.5)$ & $-47(365)$ & $-0.06(0.391)$ & 0.819 \\
\hline
\end{tabular}

${ }^{2} \mathrm{P}=0.0386$ two-sample t-test; ${ }^{3} \mathrm{P}=0.0481$ two-sample t-test; other comparisons were not significant

suggested improvement in $\triangle \mathrm{FVC} \%$ (nominal $\mathrm{P}=0.0386$ ) and $\triangle \mathrm{FVC} \mathrm{mL}$ (nominal $\mathrm{P}=0.0481$ ) for lenabasum $20 \mathrm{mg}$ vs $\mathrm{PBO}$. Improvement in FVC was also seen in subjects on established IST who had ILD at baseline, lenabasum $20 \mathrm{mg}$ vs PBO mACR CRISS score demonstrated a ceiling effect and correlated most highly with $\triangle$ mRSS $(r=-0.739)$ and moderately with MDGA $(-0.432)$, HAQ-DI (-0.362), FVC\% (0.366), and PtGA (-0.288)

Conclusion: Lenabasum was safely used in this study. Unexpectedly high improvement on background IST, especially MMF, has not been previously reported at this level. The primary endpoint was not met. Post-hoc analyses showed greater improvement in lenabasum- vs PBO-treated subjects who were not on background IST and those on established IST, including subjects with ILD. Disclosure of Interests: Robert Spiera Consultant of: Abbvie, Roche-Genetech, GSK, CSL Behring, Sanofi, Janssen, Chemocentryx, Formation Biologics, Mitsubishi Tanabe, Grant/research support from: Roche-Genetech, GSK, Boehringer Ingelheim, Chemocentryx, Corbus, Formation Biologics, Sanofi, Inflarx, Astra Zeneca, Kadmon, Masataka Kuwana Speakers bureau: Boehringer-Ingelheim, Chugai, Janssen, Consultant of: Boehringer-Ingelheim, Chugai, Corbus, Grant/ research support from: Boehringer-Ingelheim, Chugai, MBL, Ono Pharmaceuticals, Tanabe-Mitsubishi, Dinesh Khanna Shareholder of: Eicos Sciences, Inc (less than 5\%). Leadership/Equity position - Chief Medical Officer, CiviBioPharma/Eicos Sciences, Inc, Consultant of: Acceleron, Actelion, Abbvie, Amgen, Bayer, Boehringer Ingelheim, CSL Behring, Corbus, Gilead, Galapagos, Genentech/Roche, GSK, Horizon, Merck, Mitsubishi Tanabe Pharma, Sanofi-Aventis, and United Therapeutics, Grant/research support from: NIH, Immune Tolerance Network, Bayer, BMS, Horizon, Pfizer, Laura Hummers Consultant of: CSL Behring, Boehringer Ingelheim, Grant/research support from: Investigator for study sponsored by Corbus Pharmaceuticals. Corbus, Boehringer Ingelheim, Medpace, Kadmon, Cumberland, CSL Behring, Tracy Frech Grant/research support from: Investigator for study sponsored by Corbus Pharmaceuticals, Wendy Stevens Grant/research support from: Investigator for study sponsored by Corbus Pharmaceuticals, Jessica Gordon Grant/research support from: Investigator for study sponsored by Corbus Pharmaceuticals. Research funding for EICOS Pharmaceuticals and Cumberland Pharmaceuticals., Suzanne Kafaja Grant/ research support from: Investigator for study sponsored by Corbus Pharmaceuticals, Marco Matucci-Cerinic Consultant of: Actelion, Janssen, Inventiva, Bayer, Biogen, Boehringer, CSL Behring, Corbus, Galapagos, Mitsubishi, Samsung, Regeneron, Acceleron, MSD, Chemomab, Lilly, Pfizer, Roche, Grant/research support from: Investigator for study sponsored by Corbus Pharmaceuticals, Oliver Distler Consultant of: Consultancy relationship and/or has received research funding in the area of potential treatments for systemic sclerosis and its complications from (last three years): Abbvie, Acceleron Pharma, Amgen, AnaMar, Arxx Therapeutics, Baecon Discovery, Blade Therapeutics, Bayer, Boehringer Ingelheim, ChemomAb, Corbus Pharmaceuticals, CSL Behring, Galapagos NV, Glenmark Pharmaceuticals, GSK, Horizon (Curzion) Pharmaceuticals, Inventiva, iQvia, Italfarmaco, iQone, Kymera Therapeutics, Lilly, Medac, Medscape, Mitsubishi Tanabe Pharma, MSD, Novartis, Pfizer, Roche, Sanofi, Serodapharm, Topadur, Target Bioscience and UCB., Eun Bong Lee Grant/research support from: Investigator for study sponsored by Corbus Pharmaceuticals, Yair Levy Grant/ research support from: Investigator for study sponsored by Corbus Pharmaceuticals, Jae-Bum Jun Consultant of: Consultant to Boehringer Ingelheim Korea, Jeil Pharma, Dae Woong Pharma, Kwangdong Pharma, and Sama Pharma., Grant/research support from: Investigator for study sponsored by Corbus Pharmaceuticals, Scott Constantine Employee of: Employee of Corbus Pharmaceuticals, Nancy Dgetluck Employee of: Employee of Corbus Pharmaceuticals, Barbara White Employee of: Employee and stockholder of Corbus Pharmaceuticals, Daniel Furst Consultant of: Corbus, Galapagos, Pfizer, CSL Behring, Mitsubishi Tanabi, Actelion, Amgen, Novartis, Roche/Genentech, Gilead, Talaris, and Boehringer Ingelheim., Grant/research support from: grants from Corbus,
Galapagos, GSK, Pfizer, Talaris, CSL Behring, Mitsubishi Tanabi, Christopher Denton Consultant of: Consultancy fees and/or honoraria from Corbus, Actelion, GlaxoSmithKline, Bayer, Sanofi, Galapagos, Inventiva, Boehringer Ingelheim, Roche, CSL Behring, Acceleron, Horizon, Arxx Therapeutics DOI: 10.1136/annrheumdis-2021-eular.1795

\section{OP0172 $\quad$ BRENTUXIMAB VEDONTIN FOR SKIN INVOLVEMENT IN REFRACTORY DIFFUSE CUTANEOUS SYSTEMIC SCLEROSIS, INTERIM RESULTS OF A PHASE IIB OPEN-LABEL TRIAL}

A. Fernandez-Codina ${ }^{1,2,3}$, T. Nevskaya ${ }^{1}$, J. Pope ${ }^{1} .{ }^{1}$ Western University, Medicine, Rheumatology division, London, Canada; ${ }^{2}$ Windsor Regional Hospital Ouellette Campus, Medicine, Windsor, Canada; ${ }^{3}$ Hospital Clínic de Barcelona, Systemic Autoimmune Diseases, Barcelona, Spain

Background: Systemic sclerosis (SSc) is an autoimmune disease affecting multiple organs causing morbidity and mortality. Treatments targeting SSc skin often have limited success. The presence of CD30+ lymphocytes in skin biopsies and increased levels of serum CD30 have been reported in SSc patients ${ }^{1}$. This could constitute a new therapeutic target.

Objectives: To explore the efficacy and safety of brentuximab vedotin, a chimeric anti-CD30 antibody drug conjugate, in patients with severe active diffuse cutaneous SSc who failed multiple treatments.

Methods: This Phase Ilb, single center, open-label, investigator-initiated trial will recruit 10 patients. Brentuximab vedotin $0.6 \mathrm{mg} / \mathrm{Kg}$ was infused intravenously every 3 weeks for 48 weeks. Inclusion criteria were age $\geq 18$ years, meeting the 2013 ACR/EULAR SSc classification criteria, modified Rodnan skin score (mRSS) $\geq 15$ with $<5$ years since the first non-Raynaud's symptom and/or skin worsening despite immunosuppression. Patients were allowed to continue their standard of care medications for SSc except for rituximab. Patients with severe cardiac or pulmonary SSc involvement, severe infections, significant peripheral neuropathy, or active malignancy were excluded. The primary objective was a decrease in mRSS of $\geq 8$ at 48 weeks. The main secondary endpoint was MRSS at 24 weeks. Differences were assessed by paired t tests. Data were compared to 16 age, disease duration, mRSS and past/present use of immunosuppressors-matched controls (ratio 2-3:1) from the Canadian Scleroderma Research Group (CSRG) registry. Results: Eight of 10 patients have been recruited to date; two are in the first 8 weeks and one was withdrawn at her request after developing influenza at week 12. Five subjects ( $60 \%$ female) have reached week 24 , and 3 have completed 48 weeks. The mRSS is shown in Table 1. The $\triangle \mathrm{MRSS}$ for patients treated with brentuximab between weeks 0 and 24 was $8.2([\mathrm{Cl} 95 \% 2.8,13.6], \mathrm{p}=0.013)$ and from 0 to 48 was 15.3 ([Cl $95 \% 8.2,22.5], \mathrm{p}=0.012)$. Whereas, the $\Delta$ MRSS for the CSRG controls was 3.1 ([Cl 95\% -2, 8.2], $\mathrm{p}=0.211)$ at 48 weeks. Assuming that mRSS would at least be the same from week 24 to 48 in the 2 cases who are between 24 and 48 weeks with brentuximab, we compared the 5 cases vs controls (Figure 1). $\Delta$ MRSS for Brentuximab was 12.2 ([Cl 95\% 5.9, 18.5], $p=0.006$ No cases have developed a peripheral neuropathy and only one SAE (influenza).

Table 1.

\begin{tabular}{|c|c|c|c|c|c|c|c|}
\hline N (SD) & $\mathbf{N}$ & Age & $\begin{array}{l}\text { Disease } \\
\text { duration }\end{array}$ & $\begin{array}{l}\text { mRSS } \\
\text { week } 0\end{array}$ & $\begin{array}{c}\text { mRSS } \\
\text { week } 24\end{array}$ & $\begin{array}{c}\text { mRSS } \\
\text { week } 48\end{array}$ & $\begin{array}{c}\text { mRSS } \\
\text { week } 48^{\star \star}\end{array}$ \\
\hline Case & 5 & $60.2(9.3)$ & $4.5(2.1)$ & $33(5.2)$ & $24.8(6)$ & 15.7 (3) & $20.8(8.3)$ \\
\hline Control & 16 & $58.5(8.3)$ & $4.9(2.1)$ & $31.3(5.9)$ & $\mathrm{N} / \mathrm{D}$ & $28.1(7.5)$ & $28.1(7.5)$ \\
\hline p & & 0.731 & 0.775 & 0.559 & N/D & 0.013 & 0.079 \\
\hline
\end{tabular}

mRSS $=$ modified Rodnan skin score, N/D = no data, ${ }^{\star \star}{ }^{*}=$ comparisons including 5 cases, assuming stability in MRSS from week 24 to 48 in cases 5 and 6 


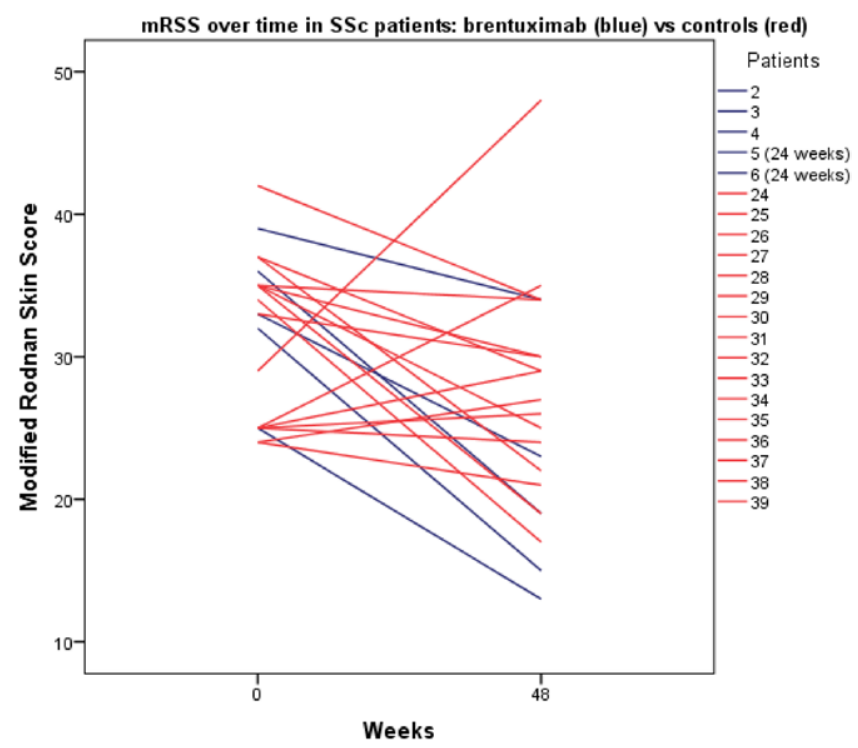

Figure 1.

Conclusion: Brentuximab vedontin already achieved the primary endpoint at 24 weeks, after half of the intended recruitment sample reached this landmark. A comparison with CSRG controls showed that mRSS only decreased significantly in patients treated with brentuximab. This interim report suggests that brentuximab vedontin might effectively improve skin involvement in patients with diffuse SSc and severe skin involvement.

REFERENCES:

[1] Mavalia C, Scaletti C, Romagnani P, et al. Type 2 helper T-cell predominance and high CD30 expression in systemic sclerosis. Am J Pathol. 1997;151(6):1751-8.

Acknowledgements: We would like to acknowledge the Canadian Scleroderma Research Group, Louise Vanderhoek, Sara Macdonald Hewitt and Jillian Bylsma for their collaboration

Disclosure of Interests: Andreu Fernandez-Codina Consultant of: Bayer, Boehringer Ingelheim, Atheneum consulting, Tatiana Nevskaya: None declared, Janet Pope Speakers bureau: Actelion, Amgen, Abbie, Bayer, Boehringer Ingelheim, BMS, Eli Lilly, Galapagos, Gilead, Janssen, Medexus, Merck, Novartis, Pfizer, Roche, Samsung, Sandoz, Sanofi, Teva, UCB., Consultant of: Actelion, Amgen, Abbie, Bayer, Boehringer Ingelheim, BMS, Eli Lilly, Galapagos, Gilead, Janssen, Medexus, Merck, Novartis, Pfizer, Roche, Samsung, Sandoz, Sanofi, Teva, UCB., Grant/research support from: Actelion, Amgen, Abbie, Bayer, Boehringer Ingelheim, BMS, Eli Lilly, Galapagos, Gilead, Janssen, Medexus, Merck, Novartis, Pfizer, Roche, Samsung, Sandoz, Sanofi, Teva, UCB. DOI: 10.1136/annrheumdis-2021-eular.2115

\section{OP0173 REDUCTION OF SKIN FIBROSIS IN SYSTEMIC SCLEROSIS ON RITUXIMAB TREATMENT. LONG-TERM FOLLOW-UP}

L. Garzanova ${ }^{1}$, L. Ananyeva ${ }^{1}$, O. Koneva ${ }^{1}$, O. Ovsyannikova ${ }^{1}$, O. Desinova ${ }^{1}$, M. Starovoytova ${ }^{1}$, R. Shayakhmetova ${ }^{1}{ }^{1} V$ A Nasonova Research Institute of Rheumatology, Laboratory of microcirculation and inflammation, Moscow, Russian Federation

Background: A sound experience has been accumulated up to date with the use of rituximab (RTX) for treatment of systemic sclerosis (SSc). Some studies reported improvement of skin fibrosis following treatment with RTX, but long-term follow-ups are really few.

Objectives: to evaluate the effect of RTX on the manifestations of skin fibrosis in patients (pts) with SSc in the long-term follow-up.

Methods: This prospective study included 71 pts aged 46 years (17-66) on average, 59 (83\%) pts were females, mean disease duration was $5,6 \pm 4,4$ years, and mean follow-up - 42 months (12-72) (mo). Diffuse SSc was established in $42(59 \%)$ pts. All pts received glucocorticoids in low doses. $45 \%$ of pts were receiving immunosuppressants at study entry. The following parameters were evaluated: Rodnan skin score (mRSS), interdigital space(IDS) (the distance between the tips of 1 and 5 fingers at maximum extension), oral aperture (OAp) and activity index (EScSG-AI) over the periods: 12-18 mo, 24-30 mo, 36-42 mo, 48-54 mo and 60-72 mo after initiation of RTX therapy. The results are presented as: mean values, delta $(\Delta)$, median, upper and lower quartiles.
Results: RTX therapy resulted in significant decrease of disease activity index, which statistically significantly correlated with decrease of mRSS - the main indicator of the severity of skin fibrosis $(r=0,39 ; p=0,001)$. Changes in parameters by follow-up periods are presented in the Table 1.

Table 1. Changes in clinical and instrumental parameters at RTX treatment (delta; median; lower quartile; upper quartile).

\begin{tabular}{|c|c|c|c|c|c|}
\hline & $12-18 \mathrm{mo}$ & 24-30 mo & $\begin{array}{c}36-42 \mathrm{mo} \\
(\mathrm{n}=36)\end{array}$ & $\begin{array}{c}48-54 \mathrm{mo} \\
(n=24)\end{array}$ & $60-72 \mathrm{mo}$ \\
\hline$\frac{\text { Parameters }}{\Delta \text { mRSS }}$ & $\begin{array}{c}(\mathbf{n}=71) \\
3,32[3.3 ; 0 ; 8] \\
p=0,001\end{array}$ & $\begin{array}{c}(\mathbf{n}=\mathbf{5 5}) \\
5,4[3 ; 0 ; 10] \\
p=0,001\end{array}$ & $\begin{array}{c}(n=36) \\
5,1[3,5 ; 0 ; 9] \\
p=0,001\end{array}$ & $\begin{array}{c}(\mathbf{n}=\mathbf{2 4}) \\
5,3[3 ; 0 ; 10] \\
p=0,001\end{array}$ & $\begin{array}{c}(\mathbf{n}=17) \\
7,3[5 ; 1 ; 14] \\
p=0,001\end{array}$ \\
\hline$\Delta O A p, c m$ & 0,24 & 0,26 & 0,39 & 0,31 & 0,36 \\
\hline & $\begin{array}{c}{[0,1 ; 0 ; 0,5]} \\
p=0,0009 \\
1,49\end{array}$ & $\begin{array}{c}{[0,1 ; 0 ; 0,6]} \\
p=0,0006 \\
1,64\end{array}$ & $\begin{array}{c}{[0,2 ; 0 ; 0,8]} \\
\mathrm{p}=0,004 \\
1,11\end{array}$ & $\begin{array}{c}{[0.3 ; 0 ; 0,7]} \\
p=0,006 \\
2\end{array}$ & $\begin{array}{c}{[0,2 ; 0 ; 0,8]} \\
p=0,009 \\
2,17\end{array}$ \\
\hline $\begin{array}{l}\Delta \text { Activity index } \\
\text { (EScSG-AI) }\end{array}$ & $\begin{array}{c}{[1,5 ; 0 ; 2,5]} \\
p=0,001\end{array}$ & $\begin{array}{c}{[1,5 ; 0 ; 2,5]} \\
p=0,001\end{array}$ & $\begin{array}{c}{[1 ; 0 ; 2]} \\
p=0,0001\end{array}$ & $\begin{array}{c}{[2 ; 1 ; 3]} \\
p=0,0001\end{array}$ & $\begin{array}{c}2,17 \\
{[2 ; 1,5 ; 2]} \\
p=0,0001\end{array}$ \\
\hline $\begin{array}{l}\text { Cumulative dose } \\
\text { of RTX, g }\end{array}$ & $1,43 \pm 0,6$ & $2,97 \pm 0,8$ & $3,45 \pm 1,3$ & $3,96 \pm 1,1$ & $5,15 \pm 1,7$ \\
\hline
\end{tabular}

Decreasing of mRSS statistically significantly correlated with increasing cumulative dose of $\operatorname{RTX}(r=0,29 ; p=0,01)$. Decreasing disease activity index correlated with increasing cumulative dose of $\operatorname{RTX}(r=-0,37 ; p=0,01)$. IDS improvement was documented at all assessment time periods, although statistically insignificant.

Conclusion: The results of this study confirm reported positive effect of RTX on the reduction of skin fibrosis in SSc. Long-term follow-up demonstrated steadily decreasing skin fibrosis and improvement of microstomia with increasing oral aperture in paralle with a decrease of the disease activity index and increasing cumulative dose of RTX.

Disclosure of Interests: None declared

DOI: 10.1136/annrheumdis-2021-eular.2860

\section{\begin{tabular}{|l|l|l|l}
\hline OP0174 SUBCLINICAL INTERSTITIAL LUNG DISEASE IS \\
\hline
\end{tabular} FREQUENT AND PROGRESSES ACROSS DIFFERENT CONNECTIVE TISSUE DISEASES}

A. M. Hoffmann-Vold ${ }^{1}$, H. Andersson ${ }^{1}$, S. Reiseter ${ }^{2}$, H. Fretheim ${ }^{1}$, I. Barua ${ }^{1}$, T. Garen ${ }^{1}, \varnothing$. Midtvedt', R. Gunnarsson ${ }^{1}$, M. Durheim ${ }^{3}$, T. M. Aaløkken ${ }^{4}, \varnothing$. Molberg $^{1}$. ${ }^{1}$ Oslo University Hospital, Rheumatology, Oslo, Norway; ${ }^{2}$ Akershus University Hospital, Internal Medicine, Oslo, Norway; ${ }^{3}$ Oslo University Hospital, Respiratory Medicine, Oslo, Norway; ${ }^{4}$ Oslo University Hospital, Radiology, Oslo, Norway

Background: Based on the argument that symptoms define disease, physicians commonly apply the terms "preclinical" or "subclinical" disease to describe patients with disease-related findings but no accompanying symptoms for connective tissue disease associated interstitial lung disease (CTD-ILD). The term subclinical frequently applies to patients with mild ILD changes on high resolution chest tomography (HRCT), normal forced vital capacity (FVC), and without respiratory symptoms. Previous work in systemic sclerosis (SSc)-ILD did show that patients with even minor extent of ILD at baseline often progressed and had increased mortality risk, suggesting that it is not appropriate to define these patients as "subclinical."

Objectives: To identify the prevalence of subclinical ILD across CTD diagnoses, and assess the rate of progression of lung fibrosis compared to CTD without ILD and with clinical ILD.

Methods: All CTD patients, including SSc, anti-synthetase syndrome (ASS) and mixed connective tissue disease (MCTD) from the Oslo University Hospital diag nosed before 2015 and assessed for the presence of ILD by HRCT were included. The year 2015 was chosen to secure an observation time of at least five years from ILD diagnosis to study end on 01.01.2021 or time of death. All patients fulfilled the respective CTD classification criteria. Subclinical ILD was defined as an ILD extent $<5 \%$ by semi-quantitative assessment of baseline HRCT, preserved lung function with FVC $>80 \%$ predicted and without respiratory symptoms. Clinical ILD was defined as $>5 \%$ extent of ILD or $<5 \%$ extent of ILD on HRCT with respiratory symtoms or FVC $<80 \%$. The outcome was ILD progression, defined as increasing extent of ILD from basline to follow-up HRCT by semi-quantitative assessment. Vital status was available in all patients and mortality was evaluated. Descriptive statistical analyses were conducted and time to ILD progression determined by Kaplan-Meier estimates. Results: We identified 525 CTD patients, including 296 with SSc, 135 with MCTD and 94 with ASS who had conducted a baseline HRCT. Of these, 227 (43\%) had no ILD, 67 (13\%) subclinical and 231 (44\%) clinical ILD (Table). Of the 67 subclinical ILD patients, 45 (15\%) had SSc, 13 (10\%) MCTD and $9(10 \%)$ ASS of thespecific cohorts. Over a median time of 4.5 years between baseline and follow-up HRCT, 95/395 (24\%) showed progression of ILD, including 72 (26\%) SSc and $23(19 \%)$ MCTD patients. Disease progression frequently occurred in both subclinical ILD (38\%) and clinical ILD (51\%) patients (Figure). Age, gender underlying CTD, and baseline lung function were not predictive for the progression of lung fibrosis. Progression was too infrequent to allow for meaningful multivariable regression analyses. After a median observation period of 12 years, $153(29 \%)$ of the patients died. The 1-, 5- and 10-year survival rates in those without ILD, subclinical and clinical ILD were 97\%/97\%/99\%, 88\%/91\%/82\%, and $82 \% / 85 \% / 68 \%(p<0.001)$, respectively. 